\title{
A Contingent Approach to Facilitating Conflict Resolution in Software Development Outsourcing Projects
}

Donghwan Cho, Gyeongnam National University of Science and Technology, Gyeongnam, South Korea

\begin{abstract}
With the wide spread of IT outsourcing, internal IT personnel have been required to change their roles from system development to organizational change agents such as securing software development outsourcing (SDO) success. Conflict resolution is critical to secure the SDO success, but the understanding of how IT personnel facilitate conflict resolution as change agents is limited. The purpose of this study is to understand the negative impact of conflicts on SDO outcomes and to investigate the moderating effect of IT personnel's conflict resolution facilitation (process facilitation, content facilitation) between conflicts and two SDO outcome dimensions (project efficiency and system effectiveness). In order to test the model, data was collected through a cross-sectional field survey using questionnaires, and a total of 144 SDO projects were used in the final analysis. Research results show that conflicts have a negative impact on both of the SDO outcome dimensions, and the effect of conflict resolution facilitation by IT personnel is contingent on the dimensions of SDO outcomes.
\end{abstract}

\section{KEYWORDS}

conflict resolution facilitation, conflict, IT outsourcing, IT personnel, project performance, software development

\section{INTRODUCTION}

"Even operational conflicts (in outsourcing arrangements) that seem quite small-typically over contracts and service - can lead to underperformance, damage relationships, and in a highly connected business eco-system, disable strategy." (Lacity and Willcocks, 2017, p. 81)

Nowadays IT (Information Technology) outsourcing is an important alternative for modern enterprises. The scope and impact of IT outsourcing has been expanded increasingly. Modern IT outsourcing includes software development, IT function outsourcing, data center, cloud service, and offshore outsourcing (Bapna et al., 2010; Gregory et al., 2009). This widespread of IT outsourcing has been making internal IT functions change their roles. Their roles have been changing mostly from delivering information systems for their organizations to system analysis, network management and especially strong change agents in their organizations (Laudon \& Laudon, 2016). They play a vital role in aligning technological developments with organizational planned changes. This paper focuses on their new emerging roles of change agents in acquiring organizational IT outsourcing success.

Despite the various types of IT outsourcing have been emerging and IT outsourcing has become a viable alternative, the effective management of IT outsourcing is still a challenge for many internal 
IT functions (Lacity \& Willcocks, 2017). This challenge has been widely documented in prior studies. Some sources estimate that more than $50 \%$ of IT outsourcing fail or perform very poorly (Ditmore, 2012; Keiser, 2014). In the context of SDO (software development outsourcing) relationships which this study focuses on among the various types of IT outsourcing, only $29 \%$ are successful, and $71 \%$ are considered failures or challenged (Wojewoda \& Hastie, 2015). Many SDO projects have failed to meet customer expectations as well as been reported to result in delayed schedule, budget overrun, and failure to business needs (Wojewoda \& Hastie, 2015; Gefen et al., 2008; Tiwana and Keil, 2004).

This high failure rate of SDO originates from the highly complex risks of SDO tasks (Choudhury $\&$ Sabherwal, 2003; Wallace \& Keil, 2004). SDO tasks wherein external service providers (or vendors) technically implement the information requirements of their client companies generally involve two types of distinct risks. The first is performance risk, that is difficult to achieve performance goals such as project schedule and budget, caused by very high complexities of software development task; the other is relational risk, wherein the parties involved in outsourcing relationships seek to achieve its own interests and exhibit opportunistic behaviors (Gefen et al., 2008; Choudhury and Sabherwal, 2003). This complex inherent risks of SDO make internal IT difficult to handle the inter-organizational development issues and prone to conflict. If the SDO risks are not effectively managed, conflicts generally arise. Therefore, the inability to resolve conflicts that arise in SDO relationships is a major cause of poor outcomes (Goo et al., 2009; Lacity and Willcocks, 2017; Rai et al., 2012).

Defined as a serious dispute between client and external service provider (e.g., Lee and Kim, 1999), the subject of SDO conflict remains an important issue in IS research. While prior research has examined the types of inter-organizational conflicts and conflict resolution styles in joint ventures, networks, consortia, alliances, and trade associations (Barringer \& Harrison, 2000; Cropper, Huxham, Ebers, \& Ring, 2008) and in various inter-organizational contexts such as natural resource rights, labor relations, international relations, volunteering, and manufacturing alliance networks (e.g., Dyer and Nobeoka, 2000; Mandell and Keast, 2009; Molnar and Rogers, 1979; Renner et al., 2007), relatively little research has examined inter-organizational conflicts in the SDO context (Lacity and Willcocks, 2017).

Prior studies on conflict in IT outsourcing mostly discovered that the capability to resolve conflicts in outsourcing relationships was significantly correlated with outsourcing outcomes (e.g., Goo et al., 2009; Lacity and Willcocks 2017; Ndubisi, 2011, 2013; Swar et al., 2012; Winkler et al., 2008; Rai et al., 2012). In these previous studies, notably some studies examined the impact of conflict resolution styles between the two outsourcing parties (e.g., integrating, accommodating, and compromising) on outsourcing outcomes (Lacity and Willcocks 2017; Ndubisi, 2011, 2013). These studies provide valuable insights into approaches to handling conflicts and managing outsourcing relationships, but they fail to consider the inherent triangular relationship comprised of vendor, client users and client IT group.

They regarded outsourcing relationship as a dyadic one comprised of client and vendor rather than a triangular one. However, if you look at the outsourcing relationships more deeply, you notice that there are three typical stakeholders comprised of vendor, client users and client IT group. On client side, user group and IT group have their own unique positions and interests that are not easy to negotiate. In the software development outsourcing, client user group has their own unique system requirements and client IT group has the intermediary and managing roles for SDO projects (Gregory et al., 2009; Choudhury and Sabherwal 2003). It is often the case that client IT personnel interact with vendors, and client users do not have many chances to directly interact with them. Therefore, system developmental issues and concerns that client users have tend to be communicated and handled through internal IT personnel, and the conflict between client users and vendors may be resolved by the intervention of internal IT rather than the direct conflict resolution between them (Goo et al., 2009). This type of conflict resolution facilitation by IT personnel has been scarce in previous studies although it is a very vital method for SDO success in practice. 
Focusing on conflict resolution facilitation by IT personnel, this study also seeks to examine the relationship between the conflict resolution facilitation types and the outsourcing outcomes. SDO outcomes are multi-faceted, mainly comprised of two very distinctive dimensions of project efficiency and system effectiveness (Gopal and Gosain 2010; Choudhury and Sabherwal 2003). Prior studies on outsourcing conflict addressed this relationship, but their findings are rather limited in terms that the outsourcing outcomes did not cover the project efficiency and system effectiveness together. Among the previous studies, Lacity and Willcocks (2017) explored how the conflict resolution styles affect client/vendor satisfaction, and Ndubisi $(2011,2013)$ examined the relationship between the conflict resolution styles and trust and commitment in outsourcing relationships. In these studies, the measure for outsourcing success was client/vendor satisfaction and trust and commitment; however, these variables can represent only a part of outsourcing success. To measure the whole picture of SDO success, both project efficiency and system effectiveness should be considered simultaneously (Gregory et al., 2009; Choudhury and Sabherwal, 2003).

This research addresses this gap found in previous studies. Therefore, the research question of this study is as follows: How do IT personnel's conflict resolution behaviors affect the SDO outcome dimensions, namely project efficiency and system effectiveness? To determine an answer, we conducted a study of 144 SDO projects performed in various South Korean companies. We focused on conflict resolution facilitating behavior by IT personnel aimed at resolving conflict between the parties involved. We differentiate between project efficiency which assesses the degree to which the software development process is adequately managed, and system effectiveness, which captures the quality-attributes of the developed software. Our study contributes to theory by examining the impact of the conflict resolution facilitation by IT personnel on SDO outcomes, which has received little attention.

\section{PRIOR WORKS AND HYPOTHESIS DEVELOPMENT}

\subsection{Conflicts in SDO}

SDO is a multifaceted and complex activity involving high level of project risks. Clients and vendors interact in many different ways to achieve their own project goals. Most SDOs are complex activities involving significant technical tasks combined with a social interaction process of various stakeholders such as users, project managers, developers, and clients (Gopal \& Gosain, 2010). In such a context, appropriate conflict resolution is vital in reconciling the diverse interests of the stakeholders and improving project performance (Lacity and Willcocks, 2017).

Table 1 summarizes the previous research on conflicts in SDO related studies. All these works provide general insights into SDO conflicts. The research shows that conflicts directly have a negative effect on SDO outcomes or moderated SDO outcomes (e.g., Kudaravalli et al., 2017; Lacity and Willcocks, 2017; Goo et al., 2009; Winkler et al., 2008; Yeh and Tsai, 2001). The research also demonstrates that at a general level, resolving conflicts have a positive impact on SDO outcomes (e.g., Kern and Willcocks, 2002; Cohen et al., 2004; Ndubisi, 2011; Rai et al., 2012; Lacity and Willcocks, 2017). Although these studies are valuable, most did not aim to assess specific SDO conflict resolution facilitation by third parties or to comprehensively consider the dimensions of SDO outcomes with the following exceptions:

Lacity and Willcocks (2017) and Ndubisi (2011) investigated how conflicts are resolved between the client and service provider in outsourcing relationships. In Ndubisi (2011), three types of conflict handling styles - integrating, accommodating, and compromising - are found to have direct and positive effect on trust and commitment in HRO (Human Resources Outsourcing) relationship. Lacity and Willcocks (2017) added three conflict resolution styles (avoiding, competing, and switch to collaborative style) to Ndubisi (2011) and specified conflict types as three: commercial, service, and relationship conflict. They found that only the collaborative and switched to collaborative styles resolved conflicts to the satisfaction of both partners in business services outsourcing relationships. 
Cohen et al. (2004) provides a different perspective from those of the above two studies, focusing on IT manager's conflict resolution facilitation role. Their focus was on conflict resolution achieved by the IT manager who is in charge of the project, rather than conflict resolution by the parties involved, namely, software testers and developers. Gopal and Gosain (2010) argues that there can be trade-off between project efficiency (adherence to schedule, budget, and user requirements) and system effectiveness (information quality, system quality, and maintainability) in SDO, and these two dimensions of SDO outcomes should be considered simultaneously for a comprehensive understanding of SDO success. Yeh and Tsai (2001) also assessed project success as including project efficiency and system effectiveness and investigated conflict potentials during software development.

\subsection{Conflict Resolution Facilitation}

There are three types of conflict management systems or dispute resolution systems in an organization, and these three types are complementary (Bendersky, 2003). These include conflicts directly between the parties in conflict, facilitating or mediating conflict resolution by third parties (those other than the parties involved), and arbitration by referring to the intervention of third parties with authority. In prior studies pertaining to conflict in SDO related research, Lacity and Willcocks (2017) and Ndubisi (2011) employed the first type of conflict resolution, i.e., resolving conflicts directly between the parties involved.

Apart from this type of conflict resolution, the focus of this research is directed toward conflict resolution facilitation by IT personnel. Facilitating conflict resolution is similar to mediation as a means of intervention by a third party to encourage voluntary consultation between the parties through various methods (Thomas, 1992). Conflict resolution facilitation implies that a person who is accepted by all the team members, neutral to the topic covered by the team, and is not accorded the official authority to make decisions performs the process of diagnosing and intervening to help improve problem recognition, problem solving, and decision making for the purpose of promoting the effectiveness of the team (Schwarz, 2002).

The main role of the conflict resolution facilitator is to help the team improve its own conflict resolution process and structure, including content facilitation and process facilitation, to increase its effectiveness (Miranda \& Bostrom, 1999). This classification is consistent with Schwarz (2002)'s basic facilitation and developmental facilitation. Content facilitation involves directly addressing a problem or issue, for example, a facilitator providing an interpretation of his or her opinions, insights, and events in a case or of facts. Process facilitation, on the other hand, provides structural procedures and general support during a meeting, encouraging team members to adhere to the agenda, encouraging them to refrain from criticizing the other party, and promoting uniform participation by all the team members.

IT personnel in a client firm typically intervene and facilitate conflict resolution between client users and external vendors because, in general, they are responsible for project success, and they understand each party's needs and situations. As part of their control over the project's success, they coordinate the differences of opinion and disagreements between users and vendors and improve project performance (Kern and Willcocks, 2002; Choudhury and Sabherwal 2003). Project planning meetings and status review meetings are the typical mechanisms for them to facilitate conflict resolution as a boundary spanning behavior (Gopal and Gosain, 2010). Code inspections and software design reviews are also employed for them to facilitate conflict resolution.

\subsection{SDO Performance}

Software development project performance has been established to be largely composed of effectiveness and efficiency dimensions (Gopal and Gosain, 2010; Wallace et al., 2004; Nidumolu, 1995). The effectiveness dimension captures the quality attributes of the developed software. This construct evaluates the degree to which the developed software meets the customer requirements and is also known as product performance (Henderson and Lee, 1992; Nidumolu, 1995). Wallace et al. 
Table 1. Previous research on conflict in SDO related studies

\begin{tabular}{|c|c|c|c|c|}
\hline Authors & Study method & $\begin{array}{l}\text { SDO conflict } \\
\text { resolution styles }\end{array}$ & $\begin{array}{l}\text { Two dimensions } \\
\text { of SDO } \\
\text { outcomes }\end{array}$ & Study results \\
\hline $\begin{array}{l}\text { Cohen et al. } \\
(2004)\end{array}$ & Case study & $\begin{array}{l}\text { Conflict } \\
\text { resolution } \\
\text { facilitation }\end{array}$ & Not investigated & $\begin{array}{l}\text { Authors investigated the antecedents of conflicts in software } \\
\text { test processes and how to manage conflicts. In order to resolve } \\
\text { conflicts between software testers and developers, project } \\
\text { managers intervene. The process described in this paper does not } \\
\text { cover the entire process of software development, but only the } \\
\text { testing process. }\end{array}$ \\
\hline Goo et al. (2009) & Survey & Not investigated & Not investigated & $\begin{array}{l}\text { Authors argued that ITO relationships are "rife with potential } \\
\text { disputes and opportunism" because of uncertainty and information } \\
\text { asymmetry in ITO relationships (p. 126). The authors found that } \\
\text { "Harmonious Conflict Resolution" positively and directly affects } \\
\text { "Trust." }\end{array}$ \\
\hline $\begin{array}{l}\text { Gopal and } \\
\text { Gosain (2010) }\end{array}$ & Survey & Not investigated & $\begin{array}{l}\text { Project } \\
\text { efficiency } \\
\text { System quality }\end{array}$ & $\begin{array}{l}\text { Authors examined the consequences of control mode choices on } \\
\text { project performance and also the moderating role of boundary } \\
\text { spanning behavior in SDO. Through boundary spanning between } \\
\text { client and vendor, mutual understanding and conflict arise. }\end{array}$ \\
\hline $\begin{array}{l}\text { Gregory et al. } \\
(2009)\end{array}$ & Case study & Not investigated & Not investigated & $\begin{array}{l}\text { Authors focused on the interpersonal relationships between } \\
\text { client team members and supplier team members in IT offshore } \\
\text { outsourcing. "Cultural intelligence" results in a "negotiated } \\
\text { culture" characterized by trust, shared understanding, and conflict } \\
\text { resolution. }\end{array}$ \\
\hline $\begin{array}{l}\text { Kern and } \\
\text { Willcocks } \\
(2002)\end{array}$ & Case studies & Not investigated & Not investigated & $\begin{array}{l}\text { Authors conducted } 12 \text { IT outsourcing cases to investigate } \\
\text { relational governance. Conflicts were resolved by managers or } \\
\text { escalated to top management. }\end{array}$ \\
\hline $\begin{array}{l}\text { Kudaravalli et } \\
\text { al. (2017) }\end{array}$ & Survey & Not investigated & Not investigated & $\begin{array}{l}\text { Team conflict mediates the relationship between design } \\
\text { collaboration centralization (also technical collaboration } \\
\text { centralization) and coordination outcomes in SDO. }\end{array}$ \\
\hline $\begin{array}{l}\text { Lacity and } \\
\text { Willcocks } \\
(2017)\end{array}$ & Case studies & $\begin{array}{l}\text { Conflict } \\
\text { resolution by the } \\
\text { parties involved }\end{array}$ & Not investigated & $\begin{array}{l}\text { Authors investigated how conflicts in BSO relationships are } \\
\text { resolved through } 13 \text { case studies. They classified the conflict } \\
\text { types into three (commercial, relationship, and service) and } \\
\text { examined how conflict resolution styles affect the client/provider } \\
\text { satisfaction. }\end{array}$ \\
\hline Ndubisi (2011) & Survey & $\begin{array}{l}\text { Conflict } \\
\text { resolution by the } \\
\text { parties involved }\end{array}$ & Not investigated & $\begin{array}{l}\text { The author explored the effects of three types of conflict handling } \\
\text { styles (integrating, accommodating, and compromising) on } \\
\text { outsourcing success (measured by trust and commitment). All } \\
\text { the three styles (integrating, accommodating, and compromising) } \\
\text { positively and directly affected "Trust" and "Commitment." }\end{array}$ \\
\hline Rai et al. (2012) & Survey & Not investigated & Not investigated & $\begin{array}{l}\text { Authors investigated if conflict resolution as a factor of relational } \\
\text { governance would substitute for goal expectations in positively } \\
\text { influencing BPO satisfaction. The study results show that } \\
\text { "Conflict Resolution" (and other relational governance factors) } \\
\text { substitutes for contractually specified goal expectations }\end{array}$ \\
\hline $\begin{array}{l}\text { Winkler et al. } \\
(2008)\end{array}$ & Case studies & Not investigated & Not investigated & $\begin{array}{l}\text { Authors viewed "conflict" as an aspect of relationship quality } \\
\text { that affects outsourcing success. Through five case studies of IT } \\
\text { offshore outsourcing, they found that power distance can result in } \\
\text { conflicts, which adversely affect outsourcing success. }\end{array}$ \\
\hline $\begin{array}{l}\text { Yeh and Tsai } \\
(2001)\end{array}$ & Survey & Not investigated & $\begin{array}{l}\text { Perceived } \\
\text { project success }\end{array}$ & $\begin{array}{l}\text { Authors examined the potential causes of conflicts and } \\
\text { reinvestigated the role of user participation in software } \\
\text { development. }\end{array}$ \\
\hline
\end{tabular}

(2004) captures this attribute by focusing on the reliability, maintainability, meeting requirements, and response time of applications, developed using five items of the Likert-scale. Nidumolu (1995) and Barki and Hartwick(2001) measure this attribute by focusing on system operational efficiency, system flexibility, and information quality.

On the contrary, the efficiency dimension assesses the degree to which the software development process is adequately managed and is also referred to as project efficiency (Gopal and Gosain, 2010; Wallace et al., 2004). This construct measures whether the software project was completed on time 
and within the budget. Budget overruns and schedule overruns characterize the efficiency dimensions of software development (Tiwana, 2004; Barki and Hatwick, 2001) and allowed more effective comparisons across diverse projects. Prior research has studied efficiency by focusing on project effort and cycle time (Harter \& Slaughter, 2003), project cost (Krishnan, Mukhopadhyay, \& Kriebel, 2004), process satisfaction (Barki and Hatwick, 2001), interaction quality (Guinan, Cooprider, \& Faraj, 1998), and quality of work (Aladwani, 2002).

As can be seen in the literature, it is possible to focus on only one aspect of the two software development project performance dimensions. However, it is critical to study both the dimensions together to completely understand the project performance. It is often easy to lower costs (and increase efficiency) by negotiating the quality aspect of the software (Pressman, 2010). Similarly, the practitioner journal discussed the widespread practice of releasing software products with known quality problems to shorten cycle times and improve efficiency (Thibodeau \& Rosencrance, 2002). Thus, in this study, we investigate the effect of conflict resolution facilitation on both the performance dimensions simultaneously. Figure 1 summarizes our proposed theoretical model.

\subsection{Hypothesis Development}

\subsubsection{Conflicts in SDO and Project Performance}

The high failure rate and high levels of conflict in SDO projects are due to the inherent complex risks of SDO projects (Choudhury and Sabherwal, 2003; Wallace et al., 2004). These risks are mainly categorized into two: the first is performance risk, which represents the challenge in achieving the goals owing to the complexity of the software development tasks, and the second is relational risk, which is exposed to the other party's opportunistic behavior as a result of collaboration between different organizations. Conflict is observed to be a major factor affecting project performance, in studies to reduce performance risks, whose subjects are predominantly internal system development (Barki \& Hartwick, 1994; Robey, Smith, \& Vijayasarathy, 1993). In these studies, conflicts appear in a variety of forms in the interaction process between users with system requirements and developers, to develop information systems; moreover, it makes a negative effect on project performance (Robey et al., 1993; Barki and Hartwick, 2001; Cohen et al., 2004).

In prior studies to reduce relational risk mostly situated in the outsourcing context, the conflict between the vendor and client is a major factor influencing outsourcing success (Winkler et al., 2008; Goo et al., 2009; Ndubisi, 2011; Rai et al., 2012; Lacity and Willcocks, 2017). In the outsourcing

Figure 1. Theoretical model

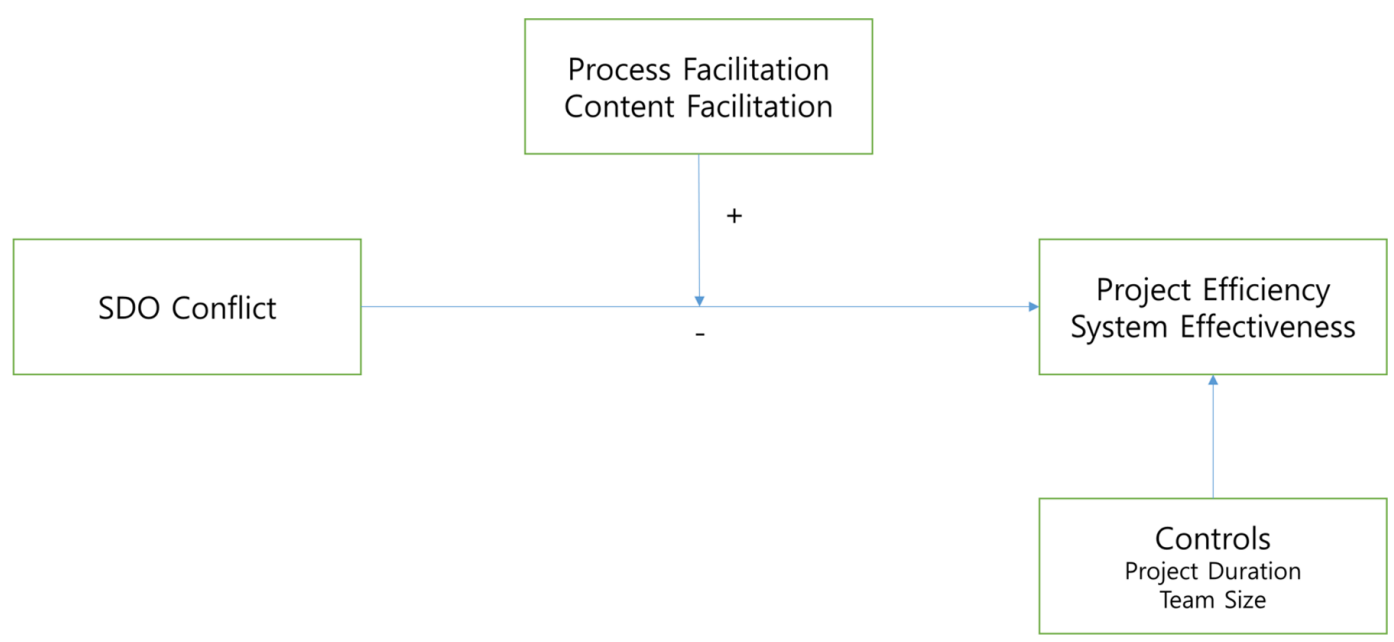


context, the relational risk is increased owing to the opportunistic behavior of the other party, which is derived from the different positions and interests of customers and vendors (Lee and Kim, 1999; Goo et al., 2009). In the case of internal development, the parties involved in conflict belong to the same organization, and they are likely to have known each other before, and the relationship among them is likely to last longer than the end of the project. On the contrary, in the case of development through outsourcing, it is highly likely that the parties involved in the conflict are not members of the same organization, such as the vendor and client. Moreover, they are not familiar with each other in advance, and most importantly, that they are susceptible to opportunistic behavior of the other party (Choudhury and Sabherwal, 2003; Goo et al., 2009). Thus, there are high possibilities of conflict between client users, who have system requirements, and vendor developers, whose tasks are developing software, and the impact of the conflict becomes even more serious.

Similar to the previous study results on conflicts in outsourcing (e.g., Goo et al., 2009; Winkler et al., 2008; Kudaravalli et al., 2017; Lacity and Willcocks, 2017), conflict will have a direct negative impact on SDO project performance in this study. However, to consider the impact of conflict on project performance comprehensively, we examine two aspects of project performance together: project efficiency and system effectiveness (Nidumolu, 1995; Barki and Hartwick, 2001). This is because the development schedule is likely to be delayed or the budget likely to be exceeded in order to improve the performance of the developed system. In addition, even if the project deadline is met and budget is not exceeded, the final system quality is likely to be low. In this study, the following hypotheses are set up pertaining to the conflict in SDO and the project performance:

Hypothesis 1a (H1a): Higher level of conflict is associated with lower level of project efficiency in SDO.

Hypothesis $1 \mathrm{~b}(\mathrm{H} 1 \mathrm{~b})$ : Higher level of conflict is associated with lower level of system effectiveness in SDO.

\subsubsection{Conflict Resolution Facilitation and Project Performance}

The role of third parties for conflict resolution in the software development process has been discussed in some previous studies. Sonnenwald(1995) observed that in the internal software development process, an agent facilitates interaction between users and developers and mediates conflict. In Linux projects, it was important to effectively coordinate conflicts among diverse participants with different perspectives (De Joode, 2004). In the SDO project, IT personnel are generally responsible for promoting interactions between vendor and client users and facilitate conflict resolution between parties with different perspectives and interests (Kern and Willcocks, 2002; Choudhury and Sabherwal, 2003). It is because they link the user departments and vendors from the outset of outsourcing agreement, communicate or broker knowledge between user departments and vendors, and have a diverse range of knowledge required to develop software (Choudhury and Sabherwal, 2003).

As the outsourcing project progresses, there will be a variety of problems and disagreements regarding the software to be developed, between the client user and the vendor. To solve such a problem and reconcile the differences, IT personnel engage in the process of resolving conflicts or occasionally intervene directly in problems or issues that cause conflicts (Miranda and Bostrom, 1999). It is challenging to achieve all specified goals of SDO projects because these goals are highly diverse and occasionally conflicting, such as process and system effectiveness. Therefore, according to project priorities or situations, it is necessary to select either process facilitation or content facilitation for conflict resolution.

Through process facilitation by IT personnel for conflict resolution, the negative impact of conflict on project efficiency can be decreased. Project planning meetings and status review meetings are effective mechanisms for this purpose (Gopal and Gosain, 2010). If the conflicts are managed and resolved effectively, the perceived quality of interactions for development can be improved, and team 
members or stakeholders can be more satisfied with the development process (Guinan et al., 1998; Barki and Hartwick, 2001). In addition, the development team can perform their job more efficiently and effectively (Aladwani, 2002).

Through process facilitation by IT personnel for conflict resolution, the negative impact of conflict on system effectiveness can also be decreased. For this purpose, code inspections and software design reviews can be employed (Gopal and Gosain, 2010). The intervention of IT personnel provides customers and vendors an opportunity to understand what the other party needs and wants and can help develop the high-quality system desired by the users. The operational efficiency and maintenance of the software can be improved, resulting in higher system effectiveness. These arguments lead to the following hypotheses:

Hypothesis 2a (H2a): Process facilitation by IT personnel for conflict resolution will positively moderate the relationship between conflicts and project efficiency in SDO.

Hypothesis $2 \mathrm{~b}(\mathrm{H} 2 \mathrm{~b})$ : Process facilitation by IT personnel for conflict resolution will positively moderate the relationship between conflicts and system effectiveness in SDO.

Apart from process facilitation, IT personnel conduct content facilitation for conflict resolution in SDO. Thereby, the negative impact of conflict on project efficiency can be decreased. Content facilitation is the intervention that directly addresses the problem or issue being discussed. Specifically, it is the intervention where in the facilitator provides his or her opinion or insight into the problem and an interpretation of facts or events (Miranda and Bostrom, 1999). During the project planning meetings and status review meetings, IT personnel can undertake content facilitation activities (Gopal and Gosain, 2010). The problem or issue causing the conflicts can be solved in a relatively shorter time with his/her interventions. Thus, the project schedule and budget can be met, resulting in project efficiency enhancement (Nidumolu, 1995; Barki and Hartwick, 2001).

Through content facilitation by IT personnel for conflict resolution, the negative impact of conflict on system effectiveness can be decreased. During software design reviews or code inspections, IT personnel can provide his or her opinion or insight that is likely to help to improve system effectiveness (Gopal and Gosain, 2010). This results in system quality improvements that include information accuracy, completeness, system utility, and reliability (Rivard, Poirier, Raymond, \& Bergeron, 1997). These arguments lead to the following hypotheses:

Hypothesis 3a (H3a): Content facilitation by IT personnel for conflict resolution will positively moderate the relationship between conflicts and project efficiency in SDO.

Hypothesis $3 b(\mathrm{H} 3 b)$ : Content facilitation by IT personnel for conflict resolution will positively moderate the relationship between conflicts and system effectiveness in SDO.

\section{RESEARCH METHODS}

\subsection{Sample}

In this study, data were collected through cross-sectional field survey using questionnaires. Data were collected through mail questionnaires, e-mail questionnaires, faxes, and direct visits, in order to ensure effective data-collection. A sampling frame for extracting samples was selected from 200 companies participating in the CEO courses of a Korean university and approximately 200 companies participating in the PMP (Project Management Professional) courses held in Korea. The reason for selecting these sampling frames is that it is suitably located for us to obtain these firms' management support for survey administration. The survey was anonymous to ensure strict confidentiality: No identifying information of any kind was gathered from the participants in order to ensure that they could not be identified. 
The unit of analysis was software development outsourcing project, and the population were comprised of all types of software development outsourcing projects conducted by Korean IT service firms. The questionnaires used in this study were divided into sections A and B to be responded to by the IT personnel and users of the client company, who participated in the project, respectively. This separation of questionnaire items through matched-pair surveys prevents single respondent bias or the common method bias. From the IT personnel, we received responses to the questionnaire items on conflicts and some of project performance (adherence to project schedule, budget, and initial specifications); from the users, we received responses on conflicts, conflict resolution, and all other project performance variables.

A total of 144 projects were used in the final analysis. We excluded the cases where the response was inconsistent, inaccurate, or had only one-side responses (not matched-pair). The project dimension characteristics of the collected samples are as follows: Of the software types developed through outsourcing, ERP accounted for 52, comprising 36\% of the total, followed by CRM (16), MIS (13), and SCM (10). From the project duration aspect, projects that lasted one year was 20 , accounting for $13.9 \%$ of the total, followed by 7 month projects (17). In terms of team size, there are 40 projects with 6 to 10 teams, accounting for $27.9 \%$ of the total, followed by 11 to 15 teams (25).

Differences between the respondents and non-respondents for the final sample were tested for non-response bias. The test results did not show any significant differences in the number of employees or sales revenue between these groups, indicating that non-response bias was not a problem in the studied sample.

\subsection{Measures}

All the survey items were rated on a seven-point Likert-type scale, anchored by $1=$ to a very small extent, $7=$ to a very large extent. As our model and analysis are focused on the project team level, one response such as team leader representing the project team was gathered and used for analysis.

\subsubsection{Conflict}

In this study, conflict implies the degree of conflict between client users and vendors in the development process of SDO project. To capture this unique context of conflicts in software development outsourcing, conflicts were measured using the metrics used in the previous studies on conflicts in the information systems field (Barki and Hartwick, 2001). We used the five items that measure disagreement, intervention, and negative emotions (Cronbach's alpha $=.875$ ). These items are presented in Appendix A.

\subsubsection{Conflict Resolution Facilitation}

In this study, conflict resolution facilitation distinguishes between process facilitation and content facilitation. Process facilitation is the intervention that provides a procedural structure and general support for resolving conflicts between the parties, and content facilitation is the intervention that directly addresses problems or issues discussed between the parties. In this study, measures from Miranda and Bostrom (1999) were applied to this research context of SDO. We used four items (Cronbach's alpha $=.882$ ) as process facilitation and three items (Cronbach's alpha $=.859$ ) as content facilitation.

\subsubsection{Project Performance}

SDO project performances were measured in terms of project efficiency and system effectiveness, as proposed by Nidumolu (1995). Project efficiency represents the degree to which the development process through outsourcing has progressed adequately, and was based on Barki and Hartwick (2001) and Nidumolu (1995). The first objective of every IT project is to complete the project within time and budget goals. Thus, for the project efficiency measure, three items were used to measure the time, budget, and goal achievement during the outsourcing development project (Cronbach's alpha $=.781$ ). 
System effectiveness represents the actual performance of software implemented for users, through outsourcing (Barki and Hartwick, 2001; Nidumolu, 1995). It is highly critical to capture the highly distinct features such as system operational efficiency from the various aspects of the system effectiveness. For this purpose, three items measure the reliability, response time, and how easy to use (Cronbach's alpha $=.909)$.

\subsubsection{Control Variables}

We control for other factors that could be confounding our examination of conflict resolution facilitation. For this purpose, we control for project duration and team size. First, generally, shortterm contracts tend to have a lower uncertainty than long-term contracts and a higher success rate. Secondly, larger teams have access to more resources to develop and manage the outsourced project and exhibit a higher success rate (Koh et al., 2004; Kudaravalli et al., 2017). Thus, these two variables were controlled.

\section{RESULTS}

In order to test the construct validity of the reflective latent constructs in our variables, we conducted principal component factor analysis with varimax rotation (Table 2). We excluded the measurement items which were not suitable for this study, through validity tests. Accordingly, the criterion for removing the measurement items is the one with factor loadings less than 0.5 , and the higher the factor loadings in the other constructs after the exploratory factor analysis using SPSS. Through this process, one item each from process facilitation (PF4) and content facilitation (CF1) were removed. The communalities for the items were above .6, and none of the cross-loadings were above .4 , thus showing good construct validity. In addition, as shown in Table 3, the Cronbach alpha levels for all the relevant variables are higher than .7 and therefore demonstrate good internal consistency of measurement.

Table 3 presents the descriptive statistics including the means, standard deviations, reliability, and correlations of the variables employed in this study. The correlations are considerably lower than the levels that are likely to indicate multicollinearity. To ensure that multi-collinearity does not pose a potential problem to our study, we examined the variance inflation factor (VIF) for all the independent variables and found them to be well below the acceptable level of 5 (the highest VIF statistic was 1.168) (Belsley, Kuh, \& Welsch, 1980).

To ensure that our sample size was adequate to test the research hypotheses, we conducted statistical power analysis. Following standard conventions, we assumed a power level of .8, which is considered reasonable for the social sciences (Cohen, 1988), resulting in a sample size of 68 for the number of variables used in this study. Since our sample size is 144 , it exceeds the sample size requirement.

As the data for all the constructs are gathered from survey respondents comprised of IT personnel and users, our study was designed to minimize the common method bias (Podsakoff \& Organ, 1986). Apart from this separation of questionnaire items, our study conforms to a number of procedural and statistical remedies to alleviate the potential threats that have been outlined (Podsakoff, MacKenzie, Lee, \& Podsakoff, 2003). First, as the questions concerning SDO outcomes were mixed with other questions and the survey was not described as focusing on SDO outcomes, the respondents could not be expected to make the connection between the predictors and outcomes. Secondly, the conflict and facilitation items appeared substantially before the SDO outcome items. Finally, we used Harman's single factor test to test for the bias by entering the independent and dependent variables in one factor analysis (Lindell \& Whitney, 2001). If a single factor is obtained, it could be evidence of common method bias; however, the factors obtained equaled the number of constructs entered. 
Table 2. Factor analysis results

\begin{tabular}{|c|c|c|c|c|c|}
\hline Item & Factor 1 & Factor 2 & Factor 3 & Factor 4 & Factor 5 \\
\hline Conflict1 & 0.746 & & & & \\
\hline Conflict2 & 0.778 & & & & \\
\hline Conflict 3 & 0.785 & & & & \\
\hline Conflict4 & 0.861 & & & & \\
\hline Conflict5 & 0.837 & & & & \\
\hline Process Facilitation1 & & 0.607 & & & \\
\hline Process Facilitation2 & & 0.888 & & & \\
\hline Process Facilitation3 & & 0.884 & & & \\
\hline Process Facilitation5 & & 0.763 & & & \\
\hline System Effectiveness 1 & & & 0.850 & & \\
\hline System Effectiveness 2 & & & 0.889 & & \\
\hline System Effectiveness3 & & & 0.900 & & \\
\hline Content Facilitation2 & & & & 0.610 & \\
\hline Content Facilitation3 & & & & 0.883 & \\
\hline Content Facilitation 4 & & & & 0.855 & \\
\hline Project Efficiency1 & & & & & 0.830 \\
\hline Project Efficiency2 & & & & & 0.827 \\
\hline Project Efficiency3 & & & & & 0.757 \\
\hline Eigen Values & 3.424 & 2.978 & 2.602 & 2.456 & 2.247 \\
\hline$\%$ of Variance explained & 19.0 & 16.5 & 14.5 & 13.6 & 12.5 \\
\hline
\end{tabular}

Note: All loadings smaller than .40 are not shown.

Table 3. Descriptive statistics

\begin{tabular}{|c|c|c|c|c|c|c|c|c|c|c|}
\hline & Variable & Mean & S.D. & $\begin{array}{c}\text { Cronbach } \\
\text { Alpha }\end{array}$ & 1 & 2 & 3 & 4 & 5 & 6 \\
\hline 1 & Project Duration & 11.70 & 9.74 & NA & 1 & & & & & \\
\hline 2 & Team Size & 28.85 & 41.40 & NA & 0.097 & 1 & & & & \\
\hline 3 & Conflict & 3.71 & 1.18 & 0.875 & -0.046 & -0.014 & 1 & & & \\
\hline 4 & Process Facilitation & 5.03 & 1.15 & 0.882 & -0.13 & $.187^{*}$ & -0.094 & 1 & & \\
\hline 5 & Content Facilitation & 5.17 & 1.01 & 0.859 & -0.085 & 0.027 & $-.256^{* *}$ & $.641 * *$ & 1 & \\
\hline 6 & Project Efficiency & 5.33 & 1.20 & 0.781 & $-.230 * *$ & $.222 * *$ & $-.273 * *$ & $.292 * *$ & $.337 * *$ & 1 \\
\hline 7 & System Effectiveness & 4.63 & 1.20 & 0.909 & -0.104 & 0.083 & $-.301 * *$ & $.342 * *$ & $.304^{* *}$ & $.337 * *$ \\
\hline
\end{tabular}

${ }^{*} p<0.05,{ }^{* *} p<0.01$

\subsection{Hypothesis Testing Results}

In this study, we argue that the impact of conflict on SDO outcomes is dependent on the level of conflict resolution facilitation. In addition, we hypothesize both the direct effects of conflict on SDO outcomes as well as the moderating effects of conflict resolution facilitation. Since our research model has control variables, independent variables and moderation effects, hierarchical regression analysis 
is chosen to test the hypotheses using the two dependent variables of project efficiency and system effectiveness. Hierarchical regression is a framework for model comparison rather than a statistical method, and a way to show if variables of interest explain a statistically significant amount of variance in dependent variable after accounting for all other variables (Babbie, 2013). Table 4 presents the facilitation model of conflict and SDO outcomes. We entered the variables in the regression analyses in a stepwise fashion starting with the control variables (project duration, team size), followed by the conflict variable as well as the moderator variable of process facilitation and content facilitation variables. As the final step, we entered the interaction terms for the interaction between conflict and the two types of facilitation.

\subsubsection{Project Efficiency}

Model 1 in Table 4 shows the relationship between the control variables and project efficiency. The model statistics show that project duration and team size are associated with project efficiency (the R-square is $10.5 \%$ and statistically significant). Model 2 exhibits the effect of adding the independent variables of conflict and process and content facilitation, the moderator. The model statistics indicate significant improvement over the control variables model $\left(\Delta R^{2}=16.3 \%, F\right.$ for $\left.\Delta R^{2}=3.176\right)$. Hypothesis 1a proposed a negative association between conflict and project efficiency and is supported. The next step tested the interaction between conflict and conflict resolution facilitation variables. As the model statistics show (Model 3), there is a marked improvement over the previous model, and it is significant $\left(\Delta R^{2}=20.7 \%, F\right.$ for $\left.\Delta R^{2}=3.78\right)$. However, only content facilitation out of the two conflict resolution facilitation variables moderates the effect of conflict on project efficiency. As Model 3 shows, the main effect of conflict is still significant in the presence of the interaction terms. Despite some debate, research indicates that the interaction terms can be interpreted on their own without considering the main effects in the model (Cohen et al., 2003; Jaccard et al., 1990). While hypothesis $2 \mathrm{a}$ regarding the interaction of conflict and process facilitation is not supported, hypothesis 3 a regarding the interaction of conflict and content facilitation is supported. This indicates that conflict is associated with increased project efficiency only when content facilitation is high.

To further investigate the nature of the interaction, we plotted the interaction effects for the dependent variables of project efficiency (Toothaker, Aiken, \& West, 1991). It is shown graphically in Figure 2, which exhibits the interaction between content facilitation and conflict for the model of project efficiency. Figure 2 indicates that when content facilitation is high, the negative effect of conflict is reduced and project efficiency is improved. However, when content facilitation is low, conflict has a full negative effect on performance, lowering project efficiency. Therefore, IT personnel in charge of SDO project should undertake more content facilitation in project situations marked by elevated levels of conflict in order to improve project efficiency; however, more content facilitation is not needed in project situation marked by lower level of conflict.

\subsubsection{System Effectiveness}

The same steps were followed for the hierarchical regression model of system effectiveness. Model 4 shows that the model with the control variables is not significant. The model statistics show that project duration and team size are not associated with system effectiveness (the R-square is $0.8 \%$ and statistically not significant). With the addition of the independent variables, the model statistics indicate significant improvement over the control variables model $\left(\Delta R^{2}=9.7 \%, F\right.$ for $\Delta R^{2}=4.512, p$ $<.01)$. Therefore, hypothesis $1 \mathrm{~b}$ is supported. Just as with project efficiency, Model 6, which includes the interaction terms, exhibits marked improvement over the previous model and is significant $\left(\Delta R^{2}\right.$ $=16.1 \%, F$ for $\left.\Delta R^{2}=5.164, p<.001\right)$. However, only process facilitation, out of the two conflict resolution facilitation variables, moderates the effect of conflict on system effectiveness. As Model 6 shows, the main effect of conflict is still significant in the presence of the interaction terms. While hypothesis $2 \mathrm{~b}$ regarding the interaction of conflict and process facilitation is supported, hypothesis $3 \mathrm{~b}$ regarding the interaction of conflict and content facilitation is not supported. This indicates that 
Table 4. Regression results

\begin{tabular}{|c|c|c|c|c|c|c|}
\hline & \multicolumn{3}{|c|}{ Project Efficiency } & \multicolumn{3}{|c|}{ System Effectiveness } \\
\hline & Model 1 & Model 2 & Model 3 & Model 4 & Model 5 & Model 6 \\
\hline \multicolumn{7}{|l|}{ Controls } \\
\hline Project Duration & $-0.242 * *$ & $-0.256^{* *}$ & $-0.226 * *$ & -0.076 & -0.092 & -0.047 \\
\hline Team Size & $0.239 * *$ & $0.24 * *$ & $0.219 * *$ & 0.056 & 0.058 & 0.000 \\
\hline \multicolumn{7}{|l|}{ Main Effects } \\
\hline Conflict & & $-0.237 * *$ & $-0.184 *$ & & $-0.272 * *$ & $-0.244 * *$ \\
\hline Process Facilitation & & 0.009 & 0.002 & & -0.048 & -0.082 \\
\hline Content Facilitation & & 0.044 & -0.005 & & 0.127 & 0.101 \\
\hline \multicolumn{7}{|l|}{ Moderation } \\
\hline Conflict $\mathrm{x}$ Process Facilitation & & & 0.109 & & & $0.242 * *$ \\
\hline Conflict $\mathrm{x}$ Content Facilitation & & & $0.197 *$ & & & 0.113 \\
\hline \multicolumn{7}{|l|}{ Model Statistics } \\
\hline $\mathrm{R}^{2}$ & 0.105 & 0.163 & 0.207 & 0.008 & 0.097 & 0.161 \\
\hline Adjusted $\mathrm{R}^{2}$ & 0.092 & 0.132 & 0.166 & -0.006 & 0.064 & 0.118 \\
\hline Model F & $8.188 * * *$ & $5.333 * * *$ & $5.044 * * *$ & 0.570 & $2.953^{*}$ & $3.713 * *$ \\
\hline Change in $\mathrm{R}^{2}$ & & 0.058 & 0.044 & & 0.089 & 0.064 \\
\hline $\mathrm{F}$ for Change in $\mathrm{R}^{2}$ & & $3.176^{*}$ & $3.780 *$ & & $4.512 * *$ & $5.164 * *$ \\
\hline
\end{tabular}

${ }^{*} \mathrm{p}<0.05,{ }^{* *} \mathrm{p}<0.01,{ }^{* * *} \mathrm{p}<0.001, \mathrm{~N}=144$

while conflict has a negative association with system effectiveness, the effect is reduced with increased process facilitation.

Figure 3 shows the interaction between process facilitation and conflict for the model of system effectiveness. It indicates that when process facilitation is high, the negative effect of conflict is reduced and system effectiveness is improved. However, when process facilitation is low, conflict has a full negative effect on performance, lowering system effectiveness. Therefore, IT personnel in charge of SDO project should undertake more process facilitation when the conflict level of a project is high in order to improve system effectiveness. However, when the conflict level is low, undertaking more process facilitation could be a waste of resources.

\section{DISCUSSION}

This study offers three major findings. First, conflict in SDO has a detrimental effect on SDO outcomes comprised of process efficiency and system effectiveness. It has the same negative effect on both dimensions of SDO outcomes. Therefore, IT managers need to make efforts to manage conflict in the beginning of a SDO project and to decrease the conflict in order to achieve the SDO success. Second, conflict resolution facilitation weakens the negative relationship between conflict and SDO project performance. IT managers can take process and/or content facilitation to lower the negative impact of conflict on SDO outcomes. Third, in order to mitigate the negative impact of conflict on SDO outcome dimensions, different facilitation approaches by IT personnel aimed at each project's own priorities should be exercised. This type of IT role as organizational change agents has been emerging and more significant required by changing IT trends these days (Laudon and Laudon 2016). 
Figure 2. Interaction effect between conflict and content facilitation on project efficiency



Figure 3. Interaction effect between conflict and process facilitation on system effectiveness

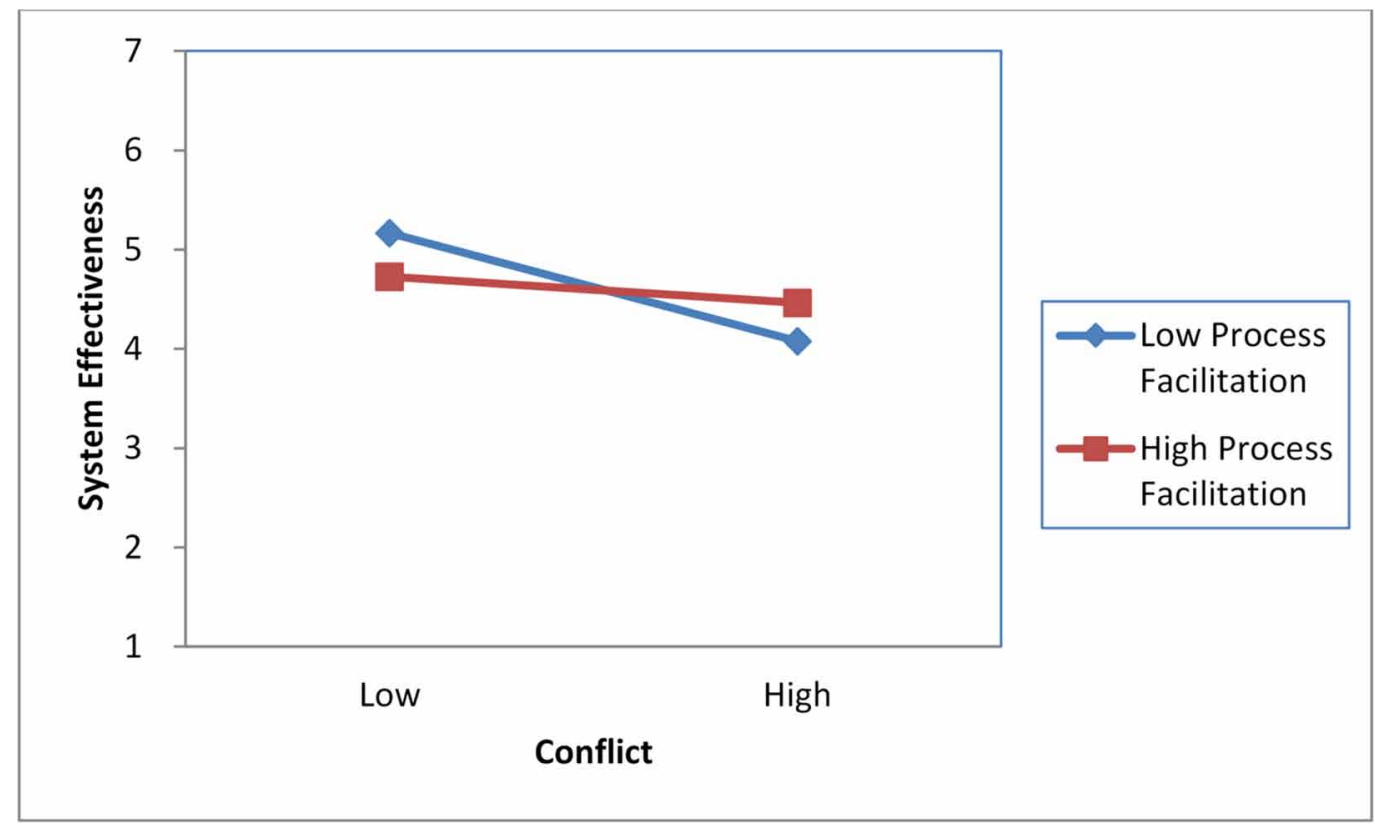

The negative impact of conflict on SDO performance dimensions weakens depending on the types of conflict resolution facilitation exercised. More specifically, in order to enhance project efficiency and reduce the detrimental effect of conflict on project efficiency, content facilitation 
should be exercised. Conversely, in order to increase system effectiveness and reduce the negative effect of conflict on system effectiveness, process facilitation is necessary. These findings highlight the practical and theoretical value of focusing on the conflict resolution facilitation efforts as team members collaborate and dispute to achieve the diverse goals of an SDO project.

\subsection{Theoretical Contributions}

Our findings contribute to the evolving research on the literature of IT outsourcing management. Previous research on outsourcing conflict (e.g. Lacity and Willcocks, 2017; Lee and Kim, 1999; Goo et al., 2009) mostly focused on conflict resolution between parties involved rather than the role of third parties such as IT personnel. Conflicts in the outsourcing context are occasionally resolved by the parties involved as well as by third parties. This research differentiates itself by focusing on the triangular relationship among client user group, IT personnel, and vendor. The conflicts between client users and vendor developers are occasionally resolved between themselves and in some cases resolved by IT personnel who are responsible for the SDO project success. This research investigated the IT personnel's role in facilitating conflict resolution between them. With this behavior, conflicts can be resolved and project performance can be improved in terms of process efficiency and system effectiveness.

The conflict in this study is highly unique in terms of the following aspects, which provide unique contributions for the conflict literature. The conflict characteristics in SDO are mixed and they comprise different types of conflicts such as task, process, and value conflict (Jehn, 1997). All these conflicts occur while the SDO project proceeds, because there are three main groups who have different view and opinions on SDO project goals and processes. These differences and conflicts tend to be rooted from intragroup conflict (project team conflict), intergroup conflict (user and developer groups), and even organizational conflict (client and vendor organization) (Robbins \& Judge, 2011). Therefore, this type of complicated conflict in SDO is very unique in nature and needs to be highlighted. Through empirical method, this research revealed the negative impact of conflict on SDO outcomes.

Another contribution of this study is to investigate the relationship between conflict and the two facets of SDO outcomes simultaneously. This contributes to the software development performance improvement literature. Prior research mostly focused on a single aspect of software project performance rather than considering both the aspects, namely, project efficiency and system effectiveness simultaneously, except a few studies (e.g., Gopal and Gosain, 2010; Choudhury and Sabherwal, 2003). Even if the project efficiency aspect of SDO project is met and achieved, the quality of the delivered software is not guaranteed. Following a similar argument, the final software quality can be improved considerably if the project is provided access to enough additional resources and time by delaying project schedule and budget. With this consideration, this study includes both aspects of software project performance and examined the possible relationships between conflict and SDO performance.

\subsection{Practical Implications}

The first imperative for IT managers is likely to be the achievement of each project goal and improvement of project performance; this influences organizational performance considering that an organization is a myriad of various project outputs. Nevertheless, it is a significantly challenging task for them to achieve all of the multi-faceted goals of software development project. This is because software development project has many diverse goals-from project adherence to schedule and budget to delivered software quality. In many cases, there are trade-offs between these process and system goals; moreover, constraints on organizational time and resources are always present (Gopal and Gosain, 2010; Pressman, 2001; Thibodeau and Rosencrance, 2002). It is critical for him or her to focus on the top priorities of the SDO project in a real world environment. The priorities tend to depend on each project's specific characteristics. Therefore, it is occasionally crucial to meet the project schedule and budget by negotiating the quality aspect of the software, and vice versa. 
IT managers can employ this study's findings on conflict resolution facilitation in a manner suited to each SDO project situation. If the priority is on project efficiency, they can produce better results through content facilitation rather than process facilitation. For example, during the project planning meetings and status review meetings, IT personnel can provide his or her opinion or insight into the problem and an interpretation of facts or events. With this type of content facilitation activities, the problem or issue causing the conflicts can be solved in a relatively shorter time. Thus the project schedule and budget can be met, resulting in project efficiency enhancement (Nidumolu, 1995; Barki and Hartwick, 2001).

If the priority is on system effectiveness, they can produce better outcomes through process facilitation rather than content facilitation. Through code inspections and software design reviews intervened by them, customers and vendors can have an opportunity to understand what the other party actually needs and wants, and to develop the high-quality system that client users actually desire(Gopal and Gosain, 2010). Thus the information quality and system quality can be improved, resulting in higher system effectiveness.

\subsection{Limitations and Future Research}

The study has limitations that point to opportunities for future research. First, the study is based on a cross-sectional data collection, and therefore, we cannot draw any inferences about how the changes in conflict affect performance or how conflict or conflict resolution is related to the different phases of the software development outsourcing life cycle. Secondly, contrary to the findings of project efficiency, the (control) relationship between the two control variables (project duration and team size) and system effectiveness was not significant. This is likely to be owing to the unique characteristics of the sample. Thirdly, instead of gathering multiple responses from a team, the study used one representative response for a team. There could be a marginally different opinion on conflict level, conflict resolution facilitation, and project performance among the members of a team.

Future research can deepen our understanding of conflict and conflict resolution by employing different research methods. For example, in contrast to cross-sectional studies, case studies deeply explore the whole SDO processes. In these processes, you can observe how the conflict occurs and IT personnel facilitate conflict resolution using various mechanisms and tools. These findings based on this type of closer observation can help for IT managers to employ intervention mechanisms and tactics necessary for SDO project success.

\section{CONCLUSION}

The changing nature of IT outsourcing has been widely documented in different streams of literature. As the outsourcing market grows rapidly and new types of outsourcing such as BSO (Business Services Outsourcing; including HR, accounting, finance, procurement, or legal service) have consistently emerged, the opportunity for collaboration with other parties has increased dramatically. Concurrently, the possibility of conflict with the other parties can also be increased drastically. Therefore, the way how to manage conflicts effectively becomes more critical and calls for further research. Scholars have only recently begun to empirically examine conflict resolution in emerging diverse outsourcing context such as BPO (Business Process Outsourcing) and BSO (Ndubisi, 2011; Rai et al., 2012; Lacity and Willcocks, 2017).

In conclusion, our study investigated the impact of conflict and conflict resolution facilitation by IT personnel on SDO outcomes, a topic that has received little attention in the literature so far. Our key finding is that the choice between process facilitation and content facilitation is contingent on the type of project outcomes quested in the project. As a result, our study underlines the need to differentiate between process and content facilitation and points to the importance of certain exercise of conflict resolution facilitation for improving project performance in software development outsourcing teams. This study questions the conventional wisdom that all types of conflict resolution facilitation are 
necessary for improving the SDO project performance dimensions. Instead, we suggest that optimal conflict resolution facilitation type may be associated with SDO project performance dimensions. Thus, this study opens up new research avenues to explore the conflict resolution mechanisms underlying various outsourcing team performance. 


\section{REFERENCES}

Aladwani, A. M. (2002). An integrated performance model of information systems projects. Journal of Management Information Systems, 19(1), 185-210. doi:10.1080/07421222.2002.11045709

Babbie, E. R. (2013). The practice of social research. Wadsworth Cengage Learning.

Bapna, R., Barua, A., Mani, D., \& Mehra, A. (2010). Cooperation, coordination, and governance in multisourcing: An agenda for analytical and empirical research. Information Systems Research, 21(4), 785-795. doi:10.1287/ isre. 1100.0328

Barki, H., \& Hartwick, J. (1994). User participation, conflict, and conflict resolution: The mediating roles of influence. Information Systems Research, 5(4), 422-438. doi:10.1287/isre.5.4.422

Barki, H., \& Hartwick, J. (2001). Interpersonal conflict and its management in information system development. Management Information Systems Quarterly, 25(2), 195-228. doi:10.2307/3250929

Barringer, B. R., \& Harrison, J. S. (2000). Walking a tightrope: Creating value through interorganizational relationships. Journal of Management, 26(3), 367-403. doi:10.1177/014920630002600302

Belsley, D., Kuh, E., \& Welsch, R. (1980). Detecting and assessing collinearity. In Regression Diagnostics (pp. 85-91). doi:10.1002/0471725153

Bendersky, C. (2003). Organizational dispute resolution systems: A complementarities model. Academy of Management Review, 28(4), 643-656. doi:.1089944410.5465/AMR.2003

Choudhury, V., \& Sabherwal, R. (2003). Portfolio of control in outsourced software development projects. Information Systems Research, 14(3), 291-314. doi:10.1287/isre.14.3.291.16563

Cohen, C. F., Birkin, S. J., Garfield, M. J., \& Webb, H. (2004). Managing conflict in software testing. Communications of the ACM, 47(1), 76-81. doi:10.1145/962081.962083

Cohen, J. (1988). Statistical power analysis for the behavioral sciences. Routledge. doi:10.1234/12345678

Cropper, S., Huxham, C., Ebers, M., \& Ring, P. S. (2008). The oxford handbook of inter-organizational relations. Oxford. doi:10.1093/oxfordhb/9780199282944.001.0001

Ditmore, J. (2012). Why IT Outsourcing Often Fails. Information Week. Retrieved from https://www. informationweek.com/it-leadership/why-it-outsourcing-often-fails/d/d-id/1105317

Dyer, J. H., \& Nobeoka, K. (2000). Creating and Managing a High-Performance Knowledge-Sharing Network: The Toyota Case. Strategic Management Journal, 21(21), 345-367. doi:10.1002/(SICI)10970266(200003)21:3<345::AID-SMJ96>3.0.CO;2-N

Gefen, D., Wyss, S., \& Lichtenstein, Y. (2008). Business familiarity as risk mitigation in software development outsourcing contracts. Management Information Systems Quarterly, 32(3), 531-551. doi:10.2307/25148855

Gopal, A., \& Gosain, S. (2010). The role of organizational controls and boundary spanning in software development outsourcing: Implications for project performance. Information Systems Research, 21(4), 960-982. doi:10.1287/isre.1080.0205

Gregory, R., Beck, R., \& Keil, M. (2013). Control Balancing in Information Systems Development Offshoring Projects. Management Information Systems Quarterly, 37(4), 1211-1232. doi:10.25300/MISQ/2013/37.4.10

Gregory, R., Prifling, M., \& Beck, R. (2009). The role of cultural intelligence for the emergence of negotiated culture in IT offshore outsourcing projects. Information Technology \& People, 22(3), $223-241$. doi:10.1108/09593840910981428

Guinan, P. J., Cooprider, J. G., \& Faraj, S. (1998). Enabling Software Development Team Performance during Requirements Definition: A Behavioral Versus Technical Approach. Information Systems Research, 9(2), 101-125. doi:10.1287/isre.9.2.101

Harter, D. E., \& Slaughter, S. A. (2003). Quality Improvement and Infrastructure Activity Costs in Software Development: A Longitudinal Analysis. Management Science, 49(6), 784-800. doi:10.1287/mnsc.49.6.784.16023 
Henderson, J. C., \& Lee, S. (1992). Managing I/S Design Teams: A Control Theories Perspective. Management Science, 38(6), 757-777. doi:10.1287/mnsc.38.6.757

Jaccard, J., Wan, C. K., \& Turrisi, R. (1990). The Detection and Interpretation of Interaction Effects Between Continuous Variables in Multiple Regression. Multivariate Behavioral Research, 25(October), $467-478$. doi:10.1207/s15327906mbr2504_4 PMID:26820822

Jehn, K. A. (1997). A Qualitative Analysis of Conflict Types and Dimensions in Groups Organizational. Administrative Science Quarterly, 42(3), 530-557. doi:10.2307/2393737

Keiser, G. (2014). Gartner Says Half of Outsourcing Projects Doomed to Failure. CRN. Retrieved from https:// www.crn.com/news/channel-programs/18822227/gartner-says-half-of-outsourcing-projects-doomed-to-failure. htm? itc $=$ refresh

Kern, T., \& Willcocks, L. (2002). Exploring relationships in information technology outsourcing: The interaction approach. European Journal of Information Systems, 11(1), 3-19. doi:10.1057/palgrave.ejis.3000415

Koh, C., Ang, S., \& Straub, D. W. (2004). IT outsourcing success: A psychological contract perspective. Information Systems Research, 15(4), 356-373. doi:10.1287/isre.1040.0035

Krishnan, M. S., Mukhopadhyay, T., \& Kriebel, C. H. (2004). A decision model for software maintenance. Information Systems Research, 15(4), 396-412. doi:10.1287/isre.1040.0037

Kudaravalli, S., Faraj, S., \& Johnson, S. L. (2017). A Configurational Approach to Coordinating Expertise in Software Development Teams. Management Information Systems Quarterly, 41(1), 43-64. doi:10.25300/ MISQ/2017/41.1.03

Lacity, M., \& Willcocks, L. (2017). Conflict resolution in business services outsourcing relationships. The Journal of Strategic Information Systems, 26(2), 80-100. doi:10.1016/j.jsis.2017.02.003

Laudon, K. C., \& Laudon, J. P. (2016). Management Information Systems: Managing the Digital Firm (Vol. 14). Pearson. doi:10.1590/S1415-65552003000100014

Lee, J.-N., \& Kim, Y.-G. (1999). Effect of Partnership Quality on IS Outsourcing Success: Conceptual Framework and Empirical Validation. Journal of Management Information Systems, 15(4), 29-61. doi:10.1080/07421222 .1999 .11518221

Lindell, M. K., \& Whitney, D. J. (2001). Accounting for Common Method Variance in Cross-Selectional Research Designs. The Journal of Applied Psychology, 86(1), 114-121. doi:10.1037/0021-9010.86.1.114 PMID:11302223

Mandell, M. P., \& Keast, R. (2009). Voluntary and Community Sector Partnerships: Current Inter-organizational Relations and Future Challenges. In The Oxford Handbook of Inter-Organizational Relations. Oxford. doi:10.1093/ oxfordhb/9780199282944.003.0007

Miranda, S. M., \& Bostrom, R. P. (1999). Meeting Facilitation: Process Versus Content Interventions. Journal of Management Information Systems, 15(4), 89-114. doi:10.1080/07421222.1999.11518223

Molnar, J. J., \& Rogers, D. L. (1979). A Comparative Model of Interorganizational Conflict. Administrative Science Quarterly, 24(3), 405-425. doi:10.2307/2989920

Ndubisi, N. O. (2011). Conflict handling, trust and commitment in outsourcing relationship: A Chinese and Indian study. Industrial Marketing Management, 40(1), 109-117. doi:10.1016/j.indmarman.2010.09.015

Ndubisi, N. O. (2013). Role of Gender in Conflict Handling in the Context of Outsourcing Service Marketing. Psychology and Marketing, 30(1), 26-35. doi:10.1002/mar.20586

Nidumolu, S. (1995). The effect of coordination and uncertainty on software project performance: Residual performance risk as an intervening variable. Information Systems Research, 6(3), 191-219. doi:10.1287/ isre.6.3.191

Podsakoff, P. M., MacKenzie, S. B., Lee, J. Y., \& Podsakoff, N. P. (2003). Common method biases in behavioral research: A critical review of the literature and recommended remedies. The Journal of Applied Psychology, 88(5), 879-903. doi:10.1037/0021-9010.88.5.879 PMID:14516251 
Podsakoff, P. M., \& Organ, D. W. (1986). Self-Reports in Organizational Research: Problems and Prospects. Journal of Management, 12(4), 531-544. doi:10.1177/014920638601200408

Pressman, R. S. (2010). Software Engineering: A Practitioner's Approach (7th ed.). Mc Graw Hill India. doi:10.1017/CBO9781107415324.004

Rai, A., Keil, M., Hornyak, R., \& Wüllenweber, K. (2012). Hybrid Relational-Contractual Governance for Business Process Outsourcing. Journal of Management Information Systems, 29(2), 213-256. doi:10.2753/ MIS0742-1222290208

Renner, S. S., Beenken, L., Grimm, G. W., Kocyan, A., \& Ricklefs, R. E. (2007). The evolution of dioecy, heterodichogamy, and labile sex expression in Acer. Evolution; International Journal of Organic Evolution, 61(11), 2701-2719. doi:10.1111/j.1558-5646.2007.00221.x PMID:17894810

Rivard, S., Poirier, G., Raymond, L., \& Bergeron, F. (1997). Development of a measure to assess the quality of user-developed applications. ACM SIGMIS Database, 28(3), 44-58. doi:10.1145/272657.272690

Robbins, S., \& Judge, T. (2011). Conflict and Negotiation. Organizational Behavior.

Robey, D., Smith, L. A., \& Vijayasarathy, L. R. (1993). Perceptions of Conflict and Success in Information Systems Development Projects. Journal of Management Information Systems, 10(1), 123-139. doi:10.1080/0 7421222.1993.11517993

Sabherwal, R. (2003). The evolution of coordination in outsourced software development projects: A comparison of client and vendor perspectives. Information and Organization, 13(3), 153-202. doi:10.1016/ S1471-7727(02)00026-X

Schwarz, R. (2002). The Skilled Facilitator: A Comprehensive Resource for Consultants, Facilitators, Managers, Trainers and Coaches. Jossey-Bass. Retrieved from http://library.capella.edu/login?url=http://search.proquest. com/docview/215898898? accountid=27965

Sonnenwald, D. H. (1995). Contested collaboration: A descriptive model of intergroup communication in information system design. Information Processing \& Management, 31(6), 859-877. doi:10.1016/03064573(95)00002-X

Swar, B., Moon, J., Oh, J., \& Rhee, C. (2012). Determinants of relationship quality for IS/IT outsourcing success in public sector. Information Systems Frontiers, 14(2), 457-475. doi:10.1007/s10796-010-9292-7

Thibodeau, P., \& Rosencrance, L. (2002). Users losing billions due to bugs. Computerworld.

Thomas, K. W. (1992). Conflict and conflict management: Reflections and update. Journal of Organizational Behavior, 13(3), 265-274. doi:10.1002/job.4030130307

Tiwana, A., \& Keil, M. (2004). The one-minute risk assessment tool. Communications of the ACM, 47(11), 73-77. doi:10.1145/1029496.1029497

Toothaker, L. E., Aiken, L. S., \& West, S. G. (1991). Multiple regression: Testing and interpreting interactions. The Journal of the Operational Research Society, 45(1), 119. doi:10.2307/2583960

van Wendel de Joode, R. (2004). Managing Conflicts in Open Source Communities. Electronic Markets, 14(2), 104-113. doi:10.1080/10196780410001675059

Wallace, L., \& Keil, M. (2004). Software project risks and their effect on outcomes. Communications of the ACM, 47(4), 68-73. doi:10.1145/975817.975819

Wallace, L., Keil, M., \& Rai, A. (2004). How Software Project Risk Affects Project Performance: An Investigation of the Dimensions of Risk and an Exploratory Model. Decision Sciences, 35(2), 289-321. doi:10.1111/j.00117315.2004.02059.x

Winkler, J. K., Dibbern, J., \& Heinzl, A. (2008). The impact of cultural differences in offshore outsourcingCase study results from German-Indian application development projects. Information Systems Frontiers, 10(2), 243-258. doi:10.1007/s10796-008-9068-5

Wojewoda, S., \& Hastie, S. (2015). Standish Group 2015 Chaos Report - Q\&A with Jennifer Lynch. INFOQ. Retrieved from https://www.infoq.com/articles/standish-chaos-2015 
Wuellenweber, K., Koenig, W., Beimborn, D., \& Weitzel, T. (2009). The impact of process standardization on business process outsourcing success. In Information Systems Outsourcing (3rd ed., pp. 527-548). Springer. doi:10.1007/978-3-540-88851-2_23

Yeh, Q. J., \& Tsai, C. L. (2001). Two conflict potentials during IS development. Information \& Management, 39(2), 135-149. doi:10.1016/S0378-7206(01)00088-X 


\section{APPENDIX A: SURVEY ITEMS}

$(1=$ to a very small extent, $7=$ to a very large extent $)$

Conflict (Adapted from Barki and Hartwick, 2001)

1. Were there important opinion differences between your user group and outside vendors concerning system goals and objectives, design and implementation?

2. Did the vendor interfere with your system goals and objectives?

3. Did the vendor interfere with the physical design that you desired?

4. During the project, did the vendor do things which made the users feel frustrated?

5. During the project, did the vendor do things which made the users feel angry?

Process facilitation (Adapted from Miranda and Bostrom, 1999)

1. Our company's IT personnel helped us to reconcile our differences with outside vendors.

2. If it were not for the internal IT personnel, the outcome of the disagreement with the outside vendor would have been worse.

3. Without internal IT personnel, the process of coordinating disagreements with vendors would have been more confusing.

4. We might have taken a longer time to reach a consensus if the internal IT personnel had not been present.

Content facilitation (Adapted from Miranda and Bostrom, 1999)

1. Internal IT personnel helped us better understand the unclear part of the problem with external vendors.

2. If the problem or issue with an external vendor is unclear, the internal IT personnel provide additional information (e.g. best practices or business cases) to solve the problem.

3. The internal IT personnel presented the decision criteria or alternative.

Project efficiency (Adapted from Nidumolu, 1995; Barki and Hartwick, 2001)

1. Compared to its estimated schedule, the project was completed (much earlier than scheduled - much later than scheduled).

2. Compared to its estimated cost, the project was completed (way under budget - way over budget).

3. Compared to its original specifications, the scope of the completed project is (much smaller than promised - much larger than promised).

System effectiveness (Adapted from Nidumolu, 1995; Barki and Hartwick, 2001)

1. The system is reliable (it is always up and running, runs without errors, and does what it is supposed to do).

2. The system is easy to use.

3. The system performs its functions quickly. 